\title{
Beiträge zur Kenntniss des Stützgerüstes im menschlichen Rückenmarke.
}

\author{
Von \\ Prof. Dosef Sehaffer, \\ Assistent am histologischen Institute in Wien.
}

Hierzu Tafel IV.

Vor Jahren habe ich mich mit Untersuchungen des Stützgewebes im Centralnervensystem, besonders im Rückenmarke beschäftigt und war vor Allem bemüht eine Methode zu finden, mittelst welcher die Neuroglia an Schnitten scharf gefärlot darzustellen wäre. Bis zu einem gewissen Grade war mir dies gelungen, als We igert's "Bemerkungen über das Neurogliagerüst des menschlichen Centralnervensystems" ${ }^{1}$ ) erschienen, in welchen er anch eine Methode andeutete, welche die Fasern der Neuroglia so hervorheben sollte, dass sie weder mit dem Fasergerüste der Achsencylinder, noch mit Ausläufern von Nervenzellen verwechselt werden können. Ohne das Verfahren mitzutheilen, veröffentlichte Weigert schon damals einige mittelst desselben für das menschliche Rückenmark gewonnene Resultate, welche ich durch meine Methode bestätigt sah; andererseits erwähnte Weigert auch einige Mängel, welche sein Färbeverfahren zur Zeit noch aufweise, so dass mir gerade in diesen Punkten meine Methode ergänzend cinzutreten schien. Während nämlich We i gert die Darstellung der Gliafasern an der Peripherie des Ruickenmarkes oft versagte, gelang mir gerade hier die schärfste Differenzirung derselben. Weiter bemerkt Weigert, dass den meisten bisherigen Methoden der Fehler anhafte, dass sich Fasern und Zellen gleich färben, dass der von $\mathrm{R}$ anvi er angenommene, mikrochemische Unterschied zwischen denselben nicht hervortrete; auch bei der versprochenen Färbung Weigert's ist der Kern häufig mitgefärbt. Dies ist nun bei meiner Methode nie der Fall; die Kerne sind stets ungefärbt, so dass man nach diesen Bildern

1) Anat. Anz., V. Jhg. 1890, S. 543-551. 
allein urtheilend, das Stützgewebe nur als aus selbstständigen Fasern zusammengesetzt halten möchte. Weigert's ausführliche Publication ist bis heute noch nicht erschienen und wenn anch seither die Neuroglia Gegenstand zahlreicher Untersuchungen gewesen ist und wir besonders der Golgi'schen Methode viele werthvolle Aufschlüsse über ihren Bau, ihre Entwicklung und Vertheilung verdanken, so sind bis heute die angedeuteten Vortheile meiner Gliafaserfärbung noch durch keine andere Methode übertroffen. Gerade zur Untersuchung der oberflächlichen Gliahülle reicht auch die Chromsilberbehandlung Golgi's nicht aus und giebt z. B. Köllike ${ }^{1}$ ) die Schilderung des feineren Baues dieser Gliahülle an der Hand von Carminpräparaten.

Ich nehme daher hier Veranlassung, meine Methode kur\% mitzutheilen. Als Untersuchungsobject diente mir das Rückenmark eines Hingerichteten, 'T., das ganz frisch in M üll e r'sche Flüssigkeit gebracht worden war. Die in Celloidin eingebetteten Schnitte werden zunächst nach der von mir ${ }^{2}$ ) modificirten Methode Kultschitzky's ${ }^{3}$ ) in Essigsäure-Hämatoxylin gefärbt, wobei alle markhaltigen Nervenelemente schwarz auf hellbraunem Grunde hervortreten ${ }^{4}$ ). Darauf werden die Schnitte lange Zeit,

1) Handbuch der Gewebelehre, II. Bd., 1. Theil, 1893, S. 151.

2) Sitzgsber. d. k. Acad. in Wien, Bd. 99, 1890. - Anat. Anz. V. Jhg. 1890, S. 643.

3) Anat. Anz., IV. Jhg., 1889, S. 223. - Anat. Anz., V. Jhg., 1890, S. 519.

4) M. Wolters hat im VII. Bd. der Zeitschr. f. w. Mikr., 1890, S. 466 ebenfalls eine "neue" Modifikation des Verfahrens von Kultschitaky zur Färbung der markhaltigen Nervenfasern des Centralnervensystems angegeben. Auch er wurde, wie ich, von der ursprünglichen Methode Kultschitzky's nicht befriedigt, nahm jedoch weiterhin keine Rücksicht auf die von Kultschitzky selbst angegebene Verbesserung, sowie auf meine vor und nach Kultschitzky's zweiter Mittheilung veröffentlichten Angaben. Die Methode von Wolters unterscheidet sich von der Kultschitzky's nnd meiner im Wesentlichen dadurch, dass Wolters die Färbung der Schnitte bei einer Temperatur von $45^{\circ} \mathrm{C}$. durch $24 \mathrm{Std}$. vornimmt, wobei sie selbstverständlich eine sehr intensive werden muss, die Schnitte aber auch brüchig werden und häufig Risse bekommen, was für die nachfolgen den Proceduren nicht ohne Nachtheil ist. Dem nachherigen Eintauchen der Schnitte in Müller'sche Flüssigkeit messe ich keine besondere Bedeutung zu, da es sich dabei höchstens um eine oberflächliche Lackbildung, nicht um eine Durchtränkung des Schnittes handeln kann. 
24 Stunden, in destillirtem Wasser ausgewaschen und dann sehr lange, bis zu 3 Wochen in einer schwachen, wässerigen Eosinlösung gefärbt. Beiläufig zwei Tropfen einer $1 \%$ Lösung auf $10 \mathrm{ccm}$ destillirtem Wasser reichen für 1-2 Schnitte aus; diese Verdünnung muss man beibehalten, auch wenn man viele Schnitte auf einmal färben will, nur ist dann die Quantität der Lösung entsprechend zu vermehren. Ich habe zwar die Menge gelösten Eosins, welche für einen bestimmten Kubikinhalt der Schnitte nothwendig ist, nicht bereehnet, aber so viel steht fest, dass minimale Mengen gentigen und dass die Färbung auch nur dann gelingt, wenn die Eosinlösung nicht zu stark ist. Ueberfärbung mit Eosin und nachträgliche Extraction des überschüssigen Farbstoffes mit Alkohol, also eine sogenannte regressive Färbung, wie sie Flem min ${ }^{1}$ ) genannt hat, giebt nicht dasselbe Resultat, wie eine Färbung, bei der gleichsam die minimale Menge an Farbstoff nur von einer Gewebeart, die eben die grösste Affinität zu demselben hat angezogen und gebunden wird. Dass ein ähnlicher Vorgang hier in der That stattfindet, geht daraus hervor, dass die dünne Eosinlösung von einer gewissen Schnittmenge merklich entfärbt wird und dass bei nachfolgender Alkoholbehandlung nur wenig Eosin aus dem Schnitte extrahirt werden kann, was an der geringen Fluoreszenz leicht erkannt wird. Das Eosin ist gleichsam gebunden und zwar hauptsächlich nur an eine Gewebeart, die Neuroglia ${ }^{2}$ ). Hat man die Schnitte auf

Nun erfolgt bei Wolters der energischen Färbung entsprechend eine energische Differenzirung und zwar nach der bekannten $\mathrm{Pal}$ 'schen Methode, die eine zweizeitige Anwendung erfordert. Kultschitzky entfärbt mit einem Gemische von Lithion carbon. und rothem Blutlaugensalz, ich mit der zuerst vorgeschlagenen Weigert'schen Differenzirungsflüssigkeit.

Man sieht also, dass das Verfahren von Wolters wohl den Namen einer "abgeänderten", nicht aber den einer "neuen" Methode verdient. Gegen die Erklärung von Wolters jedoch, dass die Entfärbung nach Weigert kein Resultat erzielt, muss ich meine Erfahrungen geltend machen, denen ich $j a$ auch bereits an den betreffenden Stellen Ausdruck gegeben habe.

1) Arch. f. mikrosk. Anat, Bd. 37, S. 709.

2) Dafür, dass Färbungen in starken oder gesättigten Farbflotten ganz andere Resultate geben, als die Verwendung sehr verdünnter Lösungen, lassen sich viele Beispiele anführen. Im ersten Falle scheint in der That eine mechanische Ueberladung der Gewebe mit Farbstoff 
diese Weise gentigend lange in der dünnen Eosinlösung belassen, dann werden sie entwässert, mit Bergamotte- oder Origanumöl aufgehellt und in Xylol-Damar eingeschlossen.

An den so behandelten Schnitten ergiebt sich nun zunächst eine prachtvolle Differenzirung zwischen echtem, leimgebendem Bindegewebe und der Neuroglia: die Piahülle des Rückenmarkes und der Nervenwurzeln, sowie die Gefässe erscheinen braun gefärbt, während das Faserwerk der Neuroglia einen leuchtend rothen Ton angenommen hat, der dureh die schwarzen Markscheiden der Nerven noch gehoben wird (vergl. die Figg. der Taf. IV). Besonders schön zeigen sich diese Farbenunterschiede an der Oberfläche des Rückenmarkes, wo die Neuroglia eine mehr minder entwickelte Rindenzone (G i e r k e's Gliahülle) bildet, die sich scharf von der braun gefärbten Piahülle und den in die Septa eindringenden Gefässen sondert ${ }^{1}$ ).

stattzufinden, während im letzteren Falle die grösste Affinität zwischen Farbstoff und einer bestimmten Gewebesorte die elektive Färbung dieser letzteren bedingt. So färben sich z. B. in dieser dünnen Eosinlösung glatte und quergestreifte Muskelfasern, hämoglobinhaltige Blutkörperchen und eosinophile Granula in Zellen ganz elektiv, während das leimgebende, lockere Bindegewebe desselben Schnittes ungefärbt bleibt. Dadurch treten die erwähnten Elemente distinkt hervor, was nicht der Fall ist, wenn man mit starker Eosinlösung kurz am Objectträger färbt; da erscheint alles mehr wieder intensiv roth gefärbt und vermag auch eine lange, fortgesetzte Extraction mit Alkohol nicht jene Differenzirung herbeizuführen, welche langdauerndes Verweilen in sehr verdünnter Eosinlösung bewirkt. Noch viel auffallender ist folgendes Beispiel. Die Ueberfärbung von Rückenmarkschnitten aus M ü ller'scher Flüssigkeit mit Essigsäure-Hämatoxylin und nachfolgende Entfärbung mit Weigert's Borax-Ferridcyankaliumlösung, welche Färbung wir auch bei unserer Neurogliafürbung anwenden, ermöglicht eine Sehwarzfärbung aller markhaltigen Elemente. Lässt man dagegen solche Rückenmarkschnitte lange Zeit (Wochen) in einer sehr verdünnten Lösung von Essigsäure-Hämatoxylin liegen (2--3 Tropfen auf $20 \mathrm{ccm}$ Wasser), so erhält man eine scharfe Achsencylinderfärbung; Achsencylinder, sowie Ganglienzellen und ihre gröberen Ausläufer erscheinen tief dunkel gefärbt, die Glia tuschgrau, während. die Markscheiden farblos bleiben.

So kann man durch die Anwendung ein und desselben Farbstoffes ganz entgegengesetzte Bilder erhalten.

1) Die hier beschriebene Differenzirung, von welcher die möglichst naturgetreuen Abbildungen eine Vorstellung geben, gelingt nicht immer gleich gut, ein Umstand oder Uebelstand, den diese Methode 
Für die tieferen Partien des Markmantels gegen die graue Substanz hin versagt die Methode. Die reichlichen Gliamassen um den Centralkanal erscheinen in einem mehr gelbrothen Ton und zeigen keine so scharf differenzirten Fäserchen, cin Verhalten, welches seinen Hauptgrund wohl in der immer mangelhaften Härtung der mittleren Partien grösserer Gewebestiicke haben dürfte. Möglicherweise könnte diesem Uebelstande durch Behandlung dünner Scheiben frischen, menschlichen Rückenmarkes mit M üI l e r'scher Flïssigkeit abgehalten werden, doch steht mir zur Zeit ein solches Material nicht zur Verfügung.

Dafür ist jedoch, wie erwähnt, die tinctorielle Scheidung von Bindegewebe und Neuroglia an der Oberfläclie des Markmantels eine. sehr scharfe und gestattet uns dieselbe zunächst einige Angaben über die Anordnung dieser Gewebe und ihre Betheiligung an der Bildung des Stützgerüstes des weissen Rïckenmarkmantels zu machen, was bei der Mannigfaltigkeit der herrschenden Ansichten, die vielfach weit auseinander gehen, nicht obne Interesse sein dürfte.

Schon durch die einleitenden Bemerkungen über die Färbungsergebnisse an dem Rückenmarke des Hingerichteten habe ich eine bestimmte Stellung in dicser Frage genommen, welche sich zunächst in Uebereinstimmung mit der Anschauung vieler anderen Autoren gegen die neuerdings wieder vertretene Auffassung von 0 bersteine $r$ kehrt und andererseits den feineren

mit so vielen anderen, welche auch auf theilweiser Entfärbung beruhen, theilt. Um daher nicht zu hoch gespannte Erwartungen hervorzurufen, die durch Misserfolge enttäuscht werden könnten, sei hier mit einigen Worten auf die Art und Quelle der Misserfolge hingewiesen. Bei der beschriebenen Färbemethode kommt Alles auf die möglichst exakte Markscheidenfärbung mit gleichzeitiger, vollkommener Fntfärbung der Gliafasern und unvollkommener Entfärbung der Piaelemente an. War die Entrarbung zu schwach, so bleibt oft auch die Glin schwarz gefärbt, kann daher von den markhaltigen Fasern nicht scharf abgegrenzt werden. Ist dic Markscheidenfärbung zu schwach, so hebt sich die Glia ebenfalls zu wenig vom Markmantel ab; endlich kann bei zu energischer Entfärbung der mit Essigsiure-Hämatoxylin überfärbten Schnitte (z. B. nach der Methode von Pal) auch die Pia vollkommen entfärbt werden; dann nimmt dieselbe bei der nachfolgenden Eosinfärbung ebenfalls einen rothen Ton an und wird dann, besonders im Markmantel eine Unterscheidung zwischen Glia und leimgebendem Bindegrewebe unmöglich. 
Bau der Neuroglia betrifft. Was den ersten Punkt anlangt, so ist es nothwendig, auf die Darstellung 0 bersteiner's ${ }^{1}$ ) etwas näher einzugehen. $0 \mathrm{~b}$ e r ste iner selbst betont in seinem ausgezeichneten Werke die grosse Unsicherheit in der Auffassung des Stiitzgewebes im Centralnervensysteme, kann sich aber von der alteren Auffassung, welche die bindegewebige Natur des Stützgewebes vertreten hat, nicht losmachen. Die Stützsubstanz tritt nach $O$ bersteiner wenigstens in den meisten Fällen als ein reticuläres Bindegewebe auf, aus feinen Fasern bestehend, die ein dichtes Netzwerk bilden und sich bis zu Bindegewebszellen verfolgen lassen (1. c. S. 195). Demnach hält er die Neurogliafasem für Bindegewebsfasem und die Neurogliazellen für Bindegewebszellen. Als Neuroglia bezeichnet er hingegen, ebenfalls einer älteren Ansicht folgend, jene bypothetische, - denn ihr morphologischer Nachweis ist durchaus nicht erbracht - formlose oder äusserst feinkörnige Masse, welche die Lücken zwischen den übrigen Elementen ausfüllt. Dieser Auffassung entsprechend lautet auch die Schilderung, welche 0 bersteiner vom Stützgerüste des Markmantels giebt: „Die Peripherie des Markmantels wird von den Rückenmarkshänten durch eine meist nur schmale Schichte grauer Substanz $(\tilde{\delta}-10 \mu$, ausnahmsweise aber bis gegen $100 \mu$ breit) getrennt: Rindenschicht des Rückenmarks oder Subpia (Wald e y e r)." Sie besteht aus faserigem Bindegewebe mit viel zwischengelagerter, feinkörniger Neuroglia. Von der Pia mater gehen durch die Rinde hindurch radiär dickere oder dünnere Septa in die weisse Substanz hinein, welche häufig Gefässe mitführen. Diese Septa bestehen ebenfalls aus Bindegewebe, mit mehr oder minder viel aus der Rindenschichte stammender Neuroglia.

Mit $\mathrm{Cerlach}{ }^{2}$ ), $\left.\mathrm{Schwalbe}^{3}\right)$ u. A. fasst $O \mathrm{bersteiner}$ die Rindensehichte als innere, gefässlose Schichte der Pia auf, betont auch den eirculären Verlauf der Fasern und lässt ebenfalls in den Sulcus long. dorsalis nur diese innere Piaschichte eintreten.

Der Erkenntniss, dass seiner Auffassung von der Natur des

1) Anleitung beim Studium des Baues der nervösen Centralorgane im gessunden und kranken Zustande. II. Auf. 1892.

2) Von dem Rückenmarke. - Stricker's Handbuch der Gewebelehre, 1871, S. 668.

3) Neurologie, Erlangen, 1881, S. 370. 
Stitzgewebes zweifellose Thatsachen widersprechen und dass dieselbe auf Grund der neueren histogenetischen Forschung eine Aenderung erfahren muss verschliesst sich allerdings auch 0 b e rs te iner nicht, indem er bemerkt: "Uebrigens darf auch die Anschauung nicht mehr zurückgewiesen werden, dass wir im Centralnervensystem zwei Arten faserigen Stutzgewebes unterscheiden muissen, von denen nur eine mit dem leimgebenden Bindegewebe völlig identisch ist" 1 ).

Mit dieser Bemerkung kommt $\mathrm{Obersteiner}$ bereits unserer Anschauung entgegen, welche nun an der Hand der Befunde am Rückenmarke des Hingerichteten erläntert werden soll.

An den nach der angegebenen Weise mit Essigsäure-Hämatoxylin und Eosin doppelt gefärbten Querschnitten zeigen die Bindegewebsbündel der Pia, sowie die Gefässwände eine braune Fürbung. Dieselbe ist so charakteristisch, dass man an derselben uberall das leimgebende, eclite Bindegewebe erkennen kann. Unmittelbar unter der Pia folgt eine in unserem Falle mächtig entwickelte, faserigkörnig erscheinende Zone, welche continuirlich mit zahlreichen Septen der Markmasse zusammenhängt; diese Continuität, sowie die vollständige Uebereinstimmung der Septen in Bezug auf Bau und mikrochemisches Verhalten zeigt deutlich, dass wir es mit ein und derselben Bindemasse zu thun haben, in welche die Längsbündel der markhaltigen Nerven so eingebettet sind, dass die bekannten Septa entstehen, während uber die Nervenmasse hinaus noch eine breitere Zone dieser Bindemasse vorhanden ist: die sog. graue Rindenzone der älteren Autoren, Subpia Wald ey er's. Ebenso deutlich sieht man aber, dass dieselbe ein von der Pia gänzlich verschiedenes mikrochemisches und histologisches Verhalten zeigt: sie erscheint nümlich prächtig roth (manchmal mit einem Stich ins Gelb oder Blau) gefärbt und besteht aus zahlreichen starren, drehrunden $\mathrm{Fa}$ sern, welche ein dichtes filzartiges Geflechte bilden und aus der Rindenzone oft auf lange Strecken hin als unverzweigte Fäden in die Septen einstrahlen, aus denen sie dann noch oft zwischen die einzelnen markhaltigen Nerven eindringen, welche allseitig so von den rothgefärbten Fasern umsponnen werden, dass sie sich nirgends direkt berühren. Eine andere Zwischensubstanz konnte ich nicht entdecken; so ist es wohl zweifellos, dass wir 1) 1. c. S. 196. 
in dem eben geschilderten Gewebe die Neuroglia, nnd zwar deren Fasern vor uns haben und dass die beschriebene Rindenschicht nichts anderes ist, als die oberflächliche Gliahülle von Gierke ${ }^{1}$ ), die mit der Pia gar nichts zu thun hat.

Den erwähnten, mikrochemischen Unterschied zwischen Pia und Glia lässt ausser der erwähnten Methode, auch die Vergoldung von Rückenmarksschnitten aus $M \ddot{u ̈ l} 1 \mathrm{er}$ 'scher Flüssigkeit nach Gerlach deutlich hervortreten, indem die Glia roth, alles Bindegewebe dunkel blauschwarz gefärbt erscheint. Ja, selbst an einfach mit Hämatoxylin und Eosin doppelt gefärbten Präparaten kann die rosa gefärbte Piahülle von der mehr gelbroth gefärbten Glia leicht unterschieden werden. Nahezu ganz vermischt erscheint dieser Unterschied an mittelst Carmin gefärbten Präparaten 2).

Demnach lässt sich die Neuroglia - ich citire einen Ausspruch Eding e r's ${ }^{3}$ ) - durch ihre Färbungsverhältnisse absolut von anderen Gewebsarten abgrenzen und so können wir als Ergebniss der bisherigen Betrachtungen im Gegensatz zu der Darstellung 0 bersteiner's die Behauptung aufstellen, dass die Rindenschichte des Rückenmarkes, sowie die von derselben abgehenden Septen aus einem Gewebe bestehen, welches schart von dem Piagewebe, d. i. leimgebendem Bindegewebe zu trennen ist ${ }^{4}$ ).

Damit ist vorläufig über die eigentliche Natur der Neuro-

1) Die Stützsubstanz des Centralnervensystems. I. Theil. - Arch. f. mikr. Anat., Bd. XXV, 1885, S. 510.

2) Bei der von Weigert angewendeten Tinction nimmt ebenfalls das Bindegewebe gar keine oder nur eine verwaschene Farbe an (Zur pathologischen Histologie des Neurogliafasergerüstes. Zi egler's Centralblatt, 1890, S. 730.) Auch nach einfacher Färbung mit Delafield's Hämatoxylin tritt ein Färbungsunterschied zwischen Glia und Pia auf; vergl. Bertelli, Atti della Soc. Toscana. Sc. N. Pisa, Mem. Vol. XII, 1892.

3) Vorlesungen über den Bau der nervösen Centralorgane des Menschen und der Thiere. - 4. Aufl. Leipzig, 1893, S. 16.

4) Damit fällt auch die eigenthümliche Ansicht, dass Gliagewebe in Piagewebe "übergehen" könne, wie sie von Paladino (Dei limiti precisi tra il nevroglio e gli elementi nervosi del midollo spinale etc. - Boll. d. R. Accad. Med. di Roma, Anno XIX, fasc. 2, 1893, S. A. S. 12) und besonders von Lavdowsky (s.u.) ausgesprochen worden ist, der von einem "wirklichen Uebergang der Epithelformation in die des Bindegewebes" spricht (1. c. S. 277). 
glia nichts positives, wohl aber ein wichtiges negatives Merkmal ausgesprochen.

Wir haben aber noch einen zweiten Punkt zu crörtern und zwar betrifft derselbe die Frage, ob sich am Aufbau des Septensystems ausschliesslich die Nenroglia oder daneben anch noch echtes, leimgebendes Bindegewebe betheiligt?

Eine iibersichtjiche Darstellung der darüber vorliegenden ebenso zahlreichen als versehiedenen Ansichten stösst auf grosse Schwierigkeiten; die Frage war eben schon zur Zeit von $\mathrm{Henle}$ und Merkel, ja sehon früher "hinlänglich verworren". Bevor Vire how ${ }^{1}$ ), die Ver'schiedenheit der Gerüstsubstanz in den Centralorganen von gewöhnlichem Bindegewebe crkennend erstere mit der Bezeichnnng Neuroglia zusammenfasste - wobei er sie aber nur für eine besondere Form des Bindegewebes hielt begegnen wir zumeist Darstellungen, welche mehr minder das ganze Septensystem als ein mit der Pia genetisch und morphologisch zusammenhängendes, also bindegewebiges bezeichnen. Hierher gehören $\mathrm{n}$. A. die älteste Darstellung von $\mathrm{Keuffel}{ }^{2}$ ), der sich auch $\mathrm{Arnold}{ }^{3}$ ) ansehloss und besonders Bilder und seine Schaler ${ }^{4}$ ); aber anch die späteren Darstellungen von Stilling ${ }^{5}$ ) und J. Gerlach ${ }^{6}$ ) missen hieher gerechnet werden.

Als Beispiel für die Anschaunngen dieser Autoren greife ich die Schilderung von $\mathrm{B}$ i d $\mathrm{der}$ und $\mathrm{Kupffor} \mathrm{r}^{7}$ ) herans. Nach einer sehr anschaulichen Beschreibung der Septula, sowic der

1) Ueber eine im Gehirn und Rückenmarke gefundene Substanz mit der chemischen Reaction der Cellulose. - Virchow's Arch., Bd.6, 1853. - Gesammelte Abhandlungen. Frankfurt a./M., 1856, s. 890.

2) Ueber das Rückenmark. - Reil's Archiv, Bd. X, 1811.

3) Bemerkungen über den Ban des Hirns und Rückenmarlss etc. Zürich, 1838.

4) Schilling, de textura med. spin. etc., Dorpati, 1852. - Owsjannikow, de text. med. spin. disquis. inprimis in piscibus fact., Dorpati, 1854. - Kupffer, de med. spin. textura, ratione inprimis habita indolis subst. cin., Dorpati, 1854. - Metzler, de text. mer. spin. avium, Dorpati, 1855. - Bidder und Kupffer, Untersuchungen über die Textur des Rückenmarks und die Fntwicklung seiner Formelemente. - Leipzig, 1857.

5) Neue Untersuchungen über den Bau des Rückemmarkes. Cassel, 1857-1859.

6) Von dem Rückenmark. - Stricker's Handbuch der Gewebelehre, 1871, S. 668 .

7) l. c. S. 38 . 
Stützsubstanz zwischen den einzelnen Nervenfasern im weissen Rückenmarksmantel bemerkt Bidder: „Jene netzförmig verbundenen Streifen nämlich (i. e. die radiären Septen) stehen auf der einen Seite in ununterbrochenem Zusammenhange mit der grauen Rückenmarkmasse, während sie andererseits ebenso deutlich bis in die Pia mater und deren für die vordere und hintere Spalte bestimmte Fortsätze sich verfolgen lassen .. - Diese, die einzelnen Ringe oder die Gruppen derselben umgebende Substanz ist also, wie dies schon ihr ununterbrochener Zusammenhang mit der Pia mater darthut, im Wesentlichen Bindesubstanz."

Als das Schlagwort Neuroglia gefallen war, da entbrannte der Streit um die morphologische Bedeutung derselben: ob es sich um eine homogene oder körnige Grundsubstanz, über ein reticuläres Bindegewebe oder um andere faserige Bildungen handle. $\mathrm{Zu}$ dieser Zeit jedoch trennte man bereits mehr minder scharf das fibrilläre Bindegewebe der Pia von der Bindesubstanz der Neuroglia, mochte man ïber ihren feineren Bau welche Vorstellung immer haben; man vergleiche in dieser Hinsicht $u$. A. die bekannten Darstellungen von Deiters ${ }^{1}$ ), Frommann ${ }^{2}$ ), Köliker ${ }^{3}$ ), Henle und Merkel ${ }^{4}$ ), Boll ${ }^{5}$ ) u. s. w.

Die meisten dieser Autoren schreiben jedoch neben der Neuroglia auch einem von der Pia ausgehenden oder eindringenden Bindegewebe eine Rolle bei der Septenbildung zu. Als Beispiel möge die Schilderung von $\mathrm{Henle}$ und $\mathrm{Merkel^{6 }}$ ) hier Platz finden. ${ }_{n}$ Der Querschnitt eines irgendwie erhärteten Rückenmarkes zeigt bekanntlich neben den stärkeren, in den Medianfissuren gelegenen bindegewebigen Platten eine Anzabl untergeordneter, gleichfalls von der Pia mater ausgehender Scheidewände, durch die die Fasern der weissen Substanz jeder Seiten-

1) Untersuchungen über Gehirn und Rückenmark etc. Herausgegeben von M. Schultze. - Braunschweig, 1865.

2) Untersuchungen über die normale und pathologische Anatomie des Rückenmarkes. Jena, 1864.

3) Gewebelehre, 5. Aufl., 1867, S. 266.

4) Ueber die sogenannte Bindesubstanz der Centralorgane des Nervensystems. - Centraibl. f. d. med. Wiss. 1869, No. 8 und Zeitschr. f. rat. Med. 1869, Bd. 34, S. 49.

5) Die Histiologie und Histiogenese der nervösen Centralorgane. - Arch. f. Psych. u. Nervenkrankh. 1873, Bd. IV.

6) 1. c. S. 65 . 
hälfte in gröbere und feinere Bündel abgetheilt werden .. - Indem die Pia mater die Scheidewände ins Innere sendet, treibt sie gleichsam die peripherische Schichte des Rückenmarkes vor sich her. Am Querschnitt sind, wie bereits F rom man n beobachtete, die Durchschnitte der bindegewebigen Septa jederseits von einem einigermaassen proportionirten Streifen der grauen Rindenschichte eingefasst. Dieser Beleg besteht aus verfilztem Bindegewebe oder aus feinkörniger Substanz oder aus einer Mischung von beiden, je nachdem in der äusseren Rindenschichte, - welche denselben Bau zeigt - das eine oder andere Gewebe entwickelt ist." Die Verfasser erklären demnach einen Theil des Septensystems als Derivat der Pia; davon ist jedoch das eigentliche Stroma des Rückenmarkes wohl zu unterseheiden. „Wir erklären uns demnach gegen die bindegewebige Natur des Gerüstes, in welches die Nervenfasern der weissen Substanz des Rückenmarkes eingelassen sind .... Wir betrachten dieses Gerüste als eine Dependenz der molekulären Rinde $\left.{ }^{1}\right){ }^{. "}$

Abweichend von dieser Darstellung erklären Kölliker und Boll hingegen bereits ausdruicklich, dass sich im Marke abgesehen von der Pia mater und ihrem Fortsatze in die vordere Spalte und der Adventitia grösserer Gefässe - durchans kein gewöhnliches fibrilläres Bindegewebe findet.

Nach B o 1 l besteht die ganze Neuroglia nur aus den Deiter'schen Zellen (Pinselzellen), welche an Stelle fibrillären Bindegewebes sogar die Adventitia der Gefässe bilden.

Er erkannte auch bereits, dass sie nicht etwa erst durch von der Pia mater aus eindringende Fortsätze zwischen die nervösen Elemente eingeschoben werden, sondern einen integrirenden Bestandtheil der Embryonalanlage bilden. Nach seiner Darstellung dringen von der Pia aus nur Gefässe, niemals aber eine nennenswerthe Menge Bindegewebe in die weisse Substanz ein und ist er mit dieser Auffassung, wie $\mathrm{K} \ddot{0} l l \mathrm{iker}$ eigentlich der letzten zil besprechenden Autorengruppe zuzuzählen. Auch seine Schilderung der oberflächlichen Gliahülle und ihres Verhaltens zu den Gefässen, auf die wir noch zurückkommen, ist eine mit den neuesten Beobachtungen fast vollkommen übereinstimmende und enthält vicle wichtige Beobachtungen, die heute viclfach wieder in Vergessenheit gerathen zu sein scheinen.

1) l. e. S. 74. 
Aber auch nachdem man den tiefgreifenden Unterschied zwischen Neuroglia and Bindegewebe in histologischer und histogenetischer Bezichung oder mit anderen Worten, die gemeinsame Anlage von Stütz- und Nervensubstanz allgemein erkannt hatte, wird heute noch von einer Reihe von Forschern dem Bindegewebe eine mehr minder bedeutende Rolle beim Aufban des Stützgerüstes, besonders des gröberen Septensystemes zugeschrieben ;

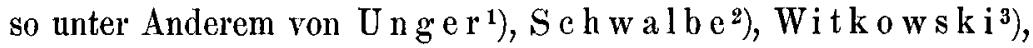
Gierke ${ }^{4}$, Kahler ${ }^{5}$ ), Lavdowsky ${ }^{6}$ ), Gegenbaur ${ }^{7}$ ).

Zur Charakteristik der Auffassung dieser dritten Autorengruppe sei zunächst die Darstellung $S \mathrm{ch}$ w al be's ${ }^{8}$ ) kurz wiedergegeben. Nach derselhen wird der Markmantel in seiner Peripherie vom Bindegewebe der Pia begrenzt. Eine Schicht des Piagewebes erbält sich auf der Oberfläche des Rückenmarkes beim Abziehen der Pia; sie wird gewöhnlich als tiefe oder circulärfaserige dieser Membran bezeichnet und besteht überwiegend aus circulären Bündeln von Bindegewebsfibrillen. Diese Schicht ist es nun, welche von ihrer inneren Oberfläche aus in unregelmässigen Abständen breitere und schmälere Bindegewebsblätter im allgemeinen in radiärer Richtung mehr oder weniger weit in die weisse Substanz hineinsendet..... Ein Septum ist vor den iibrigen durch Verlauf und Grösse besonders ausgezeichnet; es ist das Septum long. post., welches, nur ans einer Fortsetzung der tiefen Lage der Pia bestehend, bis zur hinteren geraden Commissur vordringt.

Dieses ganze Septensystem besteht nach $\mathrm{Schwalbe}$ aus echtem, leimgebenden, fibrillären Bindegewebe. Die Neuroglia,

1) Untersuchungen über die Entwicklung der centralen Nervengewebe. - Wiener Sitzgsber. d. kais. Acad. 80. Bd. 3. Abth. $187 y$.

2) Neurologie. Erlangen, 1881, S. 370. - Vgl. noch den Artikel Sehnerv desselben Autors in Gräfe und Sämisch, Handb. d, ges. Augenheilk. Bd. I, S. 341 und Zeitschr. f. Anat. u. Entw. II, S. 267.

3) Ueber die Neuroglia. - Arch. f. Psychiatrie, Bd. XIV, 1883.

4) 1. c. und II. Theil, Arch. f. mikr. Anat. Bd. 26, 1886.

5) Nervensystem in Toldt's Gewebelehre. III. Aufl. - Stuttgart, 1888, S. 179.

6) Vom Aufbau des Rückenmarkes. Histologisches über die Neuroglia und die Nervensubstanz. - Arch. f. mikr. Anat. Bd. 38, 1891, S. 264.

7) Lehrbuch der Anatomie des Menschen. 5. Aufl. - Leipzig, 1892, II. Theil, S. 338.

8) Neurologie, 1. c. S. 370 . 
welche nach $S \mathrm{ch}$ walbe 1. aus einer formlosen Grundsubstanz, 2. darin eingebetteten Fasern, die in ihrer Reaction gegen Essigsäure an elastische Fasern erinnern (von J. Gerla ch anch dafir gehalten wurden) und 3. aus platten Zellen, an welche sich die Fasern anlegen, ohne die Bedeutung von Zellausläufern zu besitzen besteht, findet sich zwischen den einzelnen Nervenfasern; und endlich beschreibt $\mathrm{Schwalbe}$ (1. e. S. 372) noch eine dritte, dünne Lage, welche mit der Hornspongiosa von $\mathrm{K} \ddot{u} \mathrm{~h}$ ne und $\mathrm{E}$ wald identisch sein soll und als graue Rindenschichte zwischen die fibrilläre Bindegewebshtille des Rückenmarkes mit den gröberen, von ihr ausstrahlenden Septen und die Neuroglia eingeschoben erscheint. Dieselbe bildet an der Oberfläche des Rückenmarks meist nur eine sehr dünne Lage von $25-50 \mu$, selten $100 \mu$ Mächtigkeit; aber auch auf die Bindegewebssepta setzt sie sich als äusserst dünne Lage eine Strecke weit fort.

Der Darstellung $\mathrm{Sch}$ walbe's schloss sich im Allgemeinen auch $\mathrm{Kahler}$ an; auch nach ihm ist das an Rückenmarksquerschnitten deutliche gröbere Septensystem zweifellos bindegewebiger Natur und in direktem Zusammenhange mit der inneren Schichte der Pia; das Septum post. ist der einzige, in vertikaler Richtung continuirliche Bindegewebszug. Die graue Rindenschichte ist eine besondere Entwicklung der Neuroglia als oberflächliche Gliahülle.

Ranvier bildet gleichsam den Uebergang zu der nächsten Antorengruppe. Er findet die Bezeichnung Neuroglia zwar verwerflich, da jedermann wisse, dass man damit das Bindegewebe des Centralnervensystems bezeichne; er betont aber bereits ausdrücklich den gemeinsamen Ursprung von Ganglien- und Gliazellen und scheint dem gewöhnlichen Bindegewebe keine Bedeutung für das Septensystem des Riickenmarkes zuzuschreiben, obgleich ich daruber in keiner seiner Darstellungen eine bestimmte Aeusserung finden konnte ${ }^{1}$ ). Ueber den feineren Bau der Neuroglia vertritt Ranvier eine besondere Anschavung, auf welche wir noch zu sprechen kommen werden. Im übrigen ist die Schilderung, welche

1) Sur les élèments conjunctifs de la moelle épinière. - Compt. rend. T. 77, 1873, p. 1299. - De la Névroglie - Ebenda, 1882, I, S. 1536. - De la Névroglie - Arch. de Physiologie, III. sér. T. I, 188', p. 177. - Technisches Lehrbuch der Histologie. Leipzig, 1888. 
er von der Anordnung der Glia in Wort und Bild (Fig. 368 des techn. Lehrbuches) giebt, eine sehr zutreffende.

Im Gegensatz zu den im Vorstehenden entwickelten Anschanungen wird aber in neuester Zeit mit grosser Entschiedenheit die Lehre vertreten, dass dem Bindegewebe gar keine Bedeutung am Aufbau des Septensystems zukomme, sondern dass dasselbe lediglich von der Neuroglia gebildet werde.

Schon Gierke neigte dieser Ansicht zu und wenn ich ihn in der Reihe der obigen Autoren nannte, so geschah es deshalb, weil er an einer Stelle ${ }^{1}$ ) bemerkt: „Die Piafortsätze, welche die Longitudinalfissuren ansfüllen, sind zum Theil Bindegewebsbündel, zum Theil aber verhornte Gliafasern", wozu er noch bemerkt, dass die Menge dieser sehr verschiedenartigen Elemente eine jedenfalls ungemein wechselnde ist. Aber aus seiner weiteren Darstellung muss man unzweifelhaft schliessen, dass er dem Bindegewebe jede grössere Bedeutung für die Bildung des Septensystems abspricht. Zum Schlusse der eitirten Stelle schon bemerkt er: "Im Allgemeinen aber scheinen die Piafortsätze und besonders ihre inneren Theile ganz hauptsächlich von den verhornten Stützfasern gebildet zu werden ${ }^{4}$ und an anderem Orte ${ }^{2}$ ): "Die aus der Pia in die weisse Substanz eintretenden Gefässe werden von einer lockeren Bindegewebsadventitia umhüllt, welche wieder die Endothelmembran (über diese siehe unten), welche sie einstülpt, als äusserste Hülle besitzt.... Das fibrilläre Bindegewebe ist also im Marke stets und immer durch die Endothelmembran eingeschlossen und auf die Umhüllung des Gefässes beschränkt. Es nimmt niemals Theil an dem Aufbau des Geriistes der weissen Substanz".

Die äIteren Ansichten Boll's und Koelliker's haben wir bereits erwähnt; die Auffassung Koelliker's hat in seinen nenesten Mittheilungen einen noch bestimmteren Ausdruck erfahren, nachdem er sich für die ektodermale Abstammung der Neuroglia ausgesprochen hat ${ }^{3}$ ). Hierher gehören noch, so weit ich den

1) l. c. I. Theil, S. 500.

2) 1. c. II. Theil, S. 157 .

3) Ueber den feineren Ban des Rïckenmarks. Vorl. Mitth. Sitzgsber. d. Würzburger Phys. med. Ges. 1890. 8. März. - Zur feineren Anatomie des centralen Nervensystems. Zweiter Beitrag: Das Rückenmark. - Zeitschr. f. wiss. Zool. Bd. 51, 1890. - Gewebelehre, 4. Aufl. II. Bd. 1. Th. Leipzig, 1893. 
Darstellungen entnehmen kann, Edinger $\left.{ }^{1}\right)$ und van Gehu ch ten ${ }^{2}$ ). Am entschiedensten hat jedoch von Lenhossék ${ }^{3}$ ) in dieser Frage Stellnng genommen, indem er jedes Vorhandensein von Bindegewebe im Rückenmarke, mit Ausnahme der das Mark durchspinnenden Blutgefässe in Abrede stellt. „Die früher so vielfach vertretenen Angaben über das Eindringen von Bindegewebesbalken von der pia mater her beruhen, wie das schon Boll erkannt batte, auf einer Verwechslung mit Gliafasern. Alle Fasergebilde in der Stuitzsubstanz des Markes stellen Fortsätze von Gliazellen dar. Das Rückenmark erscheint uns als durch und durch ectodermales Organ, das auch seine inneren Stützvorrichtungen aus eigenen Mitteln $z u$ bestreiten in der Lage ist und nur das zu seiner Ernährung dienende Canalsystem, sammt Inhalt natürlich einer fremden Hülfe entlehnt ${ }^{4}$ )".

Ich habe diese ganze Frage, die, wie man aus Vorstehenrlem ersieht, den Forschern nicht unwichtig ersehien, so ansfïhrlich behandelt, weil dies bisher in diesem Zusammenhange nicht gescheher ist und uns keine der bekannten zusammenfassenden, neueren Darstellungen von Waldeyer ${ }^{5}$ ), v. Lenhossék ${ }^{6}$ ) und Golgi ${ }^{7}$ ) über die Entwieklung dieser Frage Anfschluss giebt. Ich kann mich nun auch mit meinen eigenen Beobachtungen, zu denen ich nun zurückkehre, viel klirzer fassen.

Die Entscheidung wird nach unseren Präparaten, in denen Bindegewebe und Glia durch ihre verschiedene Färbung scharf gesondert werden können, leicht. Man sieht ausser dem allgemein anerkannten Piafortsatz, welcher sich als Duplicatur in die ventrale Fissur einsenkt und den Gefässen, welche in der von $\mathrm{Key}$

1) I, c.

2) Le système nerveux de l'homme. Lierre, 1893.

3) Zur Kenntniss der Neuroglia des menschlichen Rückenmarkes. - Verhdlgn. d. anat. Ges. V. Vers. in München, 1891, S. 193. - Der feinere Bau des Nervensystems im Lichte neuester Forschung. Berlin, Kornfeld, 1893. (Als S.-A. aus "Fortschritte der Medicin“.)

4) Fortschr. d. Med. l. c. S.-A. S. 61.

5) Ueber einige neuere Forschungen im Gebiete der Anatomie des Centralnervensystems. - Deutsche med. Woch., 1891, No. 44 u. ff. sowie separat bei Thieme, Leipzig.

6) l. c.

7) Vgl. das Referat "Nervensystem" in Merkel-Bonnet's Ergebnissen d. Anat. u. Entw., I. Bd., 1892. S. 295. 
und Retzius genau beschriebenen Weise in das Mark eintreten, da und dort an der Peripherie des Rückenmarkes kleinere Bindegewebszüge die Gliahülle durchbrechen und von Glia begleitet, eine Strecke weit in das Mark eintreten, wo sie im Allgemeinen nach kurzem radiärem Verlaufe ond allmählicher Verschmächtigung. sich verlieren. Diese kleineren Bindegewebssepten sind, wie man sich an dickeren Schnitten und an Schnittfolgen überzengen kann ganz unabhängig von Gefässen, bezüglich von der Adventitia derselben. Damit soll jedoch durchaus nicht gesagt sein, dass sie es auch immer waren, $d . h$. dass der $W e g$, anf welchem sie eingedrungen sind, nicht die Adventitia der Gefässe gewesen ist. Dies ist sogar sehr wahrscheinlich, wobei man jedoch stets die bekannte Möglichkeit der Rückbildung dieser Gefässe im Auge behalten muss, nach welcher bindegewebige Reste in Form von Septen recht wohl zurückgeblieben sein können. Im Ganzen jedoch ist das Vorkommen solcher oberflächlicher Bindegewebssepta selten und ihre Bedeutung gering. Stärkere Bindegewebsbalken auf grössere Tiefe eindringend, finden wir stets nur in Begleitung der Gefässe. Sie erlangen aber oft eine so mächtige Entwicklung und sind in so reichlicher Anzahl vorhanden, dass man ihre Betentung für das ganze stützende Skelet des Markes nicht unterschätzen kann. An Querschnitten erscheint oft die bindegewebige Adventitia so vom Gefäss abgespalten, dass man ein selbstständiges Piaseptum vor sich zu haben glaubt, eine Fehlerquelle, die man wohl im Auge behalten muss. Eine besondere Erörterung erforlert noch das dorsale mediane Septum, welches, wie wir gehört haben, von vielen Autoren als der mäehtigste und einzige in vertikaler Richtung continuirliche Bindegewebszug geschildert worden ist, während er nach v. Lenhossék, Kölliker, van Gehuchten 11. A. ebenso ein reines Gliascptum sein soll, wie die übrigen. v. Lenhossék ${ }^{1}$ ) bemerkt dariiber folgendes: Die hintersten, dem Gebiete der Commissura post. grisea angehörenden Epéndymzellen zeigen eine streng mediane Lage und dicht gedrängte Anordnung, so dass sie sich zu einem compacten Bündel, einer sagittalen Scheidewand zwischen rechter und linker Hälfte des Hinterstranges concentriren...... Dieser Streifen galt bis dahin

1) Münchner Verhlgn. l. c. S. 207 und Fortschr. d. Med. S.-A. 1. c. S. 48. 
fast allgemein als eine Einsendung der pia mater und man hat daher beharrlich von einer "hinteren Fissur" gesprochen, der allerdings von jenem Fortsatze vollkommen ausgefüllt werde. Diese Darstellung ergiebt sich nun als haltlos; das Rückenmark ist hinten unzweifelhaft ungespalten; es weist wohl einen suleus, aber keine fissura post. auf, indem das septum post., das nebenbei gesagt, oft gar nicht stärker erscheint, als die übrigen Gliasepta der weissen Substanz eine eigene Bildung des Rückenmarkes darstellt."

Diese Schilderung ist für das Objekt, das derselben zu Grunde liegt (ein $14 \mathrm{~cm} \mathrm{l}$. menschl. Embryo), vollkommen zutreffend, hat aber, wie wir sehen werden, nur theilweise Geltung für das Riickenmark des Erwachsenen. Innig verbunden mit der Frage nach der Natur des septum dorsale ist die nach dem Vorhandensein einer fissura und eines suletus dorsalis, worüber ebenfalls die Angaben bis in die neueste Zeit sehr auseinandergehen. Während die Einen heute noch von Fissuren sprechen (Lavdowsky, Key und Retrius u. A.) wollen Andere nur einen suleus dorsalis anerkennen (Goll ${ }^{1}$ ), Robinson ${ }^{2}$ ), v. Lenhossćk, v. Gehuchten u. A.). Nun verhält sich aber die Sache so, dass diese Verhältnisse nicht an der ganzen dorsalen Fläehe des Rückenmarkes die gleichen sind und kann ich hier auf die alte, aber theilweise vollkommen richtige Beschreibung von Arnold ${ }^{3}$ ) verweisen. Er schildert, wie folgt: "A Ausser der fiss. long. ant. nimmt man flurch die ganze Lünge des Rückenmarkes vom Erwachsenen keine andere wahr, weder eine auf der hintern Fläche, noch eine seitliche.... Dagegen erkennt man theils gröbere, theils feinere Furchen. Von diesen liegt eine an der hinteren Fläche in der Mitte, der Spalte vorn gerade entgegengesetzt.... . Da, wo das Rutekenmark in die Med. oblong. übergeht, findet sich hinten eine tiefe Spalte, welche sich nach unten allmählich verliert. Ebenso trifft man öfters an der Lendenanschwellung bis fast zum Ende des Rückenmarkes in der Länge

1) Beitrag zur feineren Anatomie des menschlichen Rückenmarks. - Denkschr. d. med. chir. Ges. in Zürich. Zürich, 1860. \$.133.

2) On the development of the post. colums etc. - Studies in Auatomy from the Anat. Depart. of the Owens College, Vol. I, Manchester, 1891, p. 98.

3) l. c. S. 3 u. ff. 
von 10 Linien eine hintere Spalte, die nach oben sich verliert und in die hintere Furche ubergeht. Sie erstreckt sich nicht bis zur grauen Substanz und lat eine Tiefe von 3 Linien." Meine eigenen Beobachtungen an einer Reihe von Rückenmarksquerschnitten ergaben folgendes: Uebereinstimmend mit v. Lenhossék, Koelliker u. A. finde ich das dorsale Septum vom Halsmark bis zum Beginn des Lendenmarks als reines Gliaseptum, in welchem von Stelle zu Stelle Gefässe eingebettet erscheinen. Dort, wo dies nicht der Fall ist, erscheint es in der That nicht breiter, als die übrigen Gliasepten (Fig. 1, SLP) und unterscheidet sich von ihnen nur dadurch, dass es continuirlich bis an die hintere graue Commissur reicht ${ }^{1}$ ). Während im Halsmark ein sulcus dorsalis mehr minder deutlich ausgebildet ist, fehlt ein solcher vielfach vollkommen im Dorsalmark (Fig. 1) und zeigt hier weder Pia noch Gliahülle eine Einsenkung.

Anders gestalten sich die Verhältnisse im Lenden- und Sakralmark.

Hier findet sich zunächst stets ein gut entwickelter suleus (Fig. 2), dessen Lippen, wie wir hören werden, von einer hohen

1) Angesichts dieser zweifellosen Thatsache scheint es mir möglich, dass sich jene Autoren, welche das Septum dorsale als Bindegewebsseptum beschrieben haben, eine Verwechslung zu Schulden kommen liessen, obwohl sie theilweise richtig beobachtet haben. Die meisten derselben, wie z. B. Gerlach, Schwalbe, Obersteiner beschreiben nämlich an der Pia eine tiefe, circulärfaserige Lage, welche mit der Oberfläche des Rückenmarkes so innig verbunden ist, dass sie bei Entfernung der Pia immer am Rückenmark haften bleibt. Das Septum posterius soll nun stets immer nur aus dieser inneren, cireulärfaserigen Lage bestehen. Nun zeigt die oberflächliche Gliahülle, wie wir sehen werden, dort, wo sie stärker entwickelt ist, ebenfalls einen deutlich circulärfaserigen Bau und scheint es mir nach der Fig. 226, S. 370 bei Schwalbe wahrscheinlich, dass die genannten Autoren in ihrer inneren, circulärfaserigen Lage der Pia nicht die Intima piae (Key and Retzius), sondern die oberflächliche Gliahülle vor sich gehabt und das von derselben abgehende Sept. post. fälschlich für ein Bindegewebsseptum gehalten haben. Allerdings werde ich in dieser Vermuthung durch die Schilderung Schwalbe's (s. o.), der noch eine Lage von Hornspongiosa unter der Pia beschreiht, wieder wankend gemacht. aber so viel ist sicher, dass das Septum post. von der oberflächlichen Gliahülle entspringt und die gleiche Zusammensetzung mit ihr zeigt, wenigstens im unteren Hals- und Brustmark. 
Glialage bedeckt sind (Fig. 2, GH). Auf und mit dieser Glialage senkt sich nun von beiden Seiten eine feine Lamelle der Pia ein (Fig. 2, P, PS), welche in der Tiefe des sulcus, wenn sie nicht durch ein eintretendes Gefüss auseinander gehalten werden, zu einem Bindegewebsseptum verschmelzen, welches num weiter in die Marksubstanz eindringt bis beiläufig auf ein Drittel der ganzen Länge des dorsalen Septnm. Dort verliert es sich, wie die kleineren, radiären Bindegewebssepten und wird von einem reinen Gliaseptum fortgesetzt, welches continuirlich übergeht in die zwei Glialagen, welche das Bindegewebsseptum an seinen Oberffächen und die Lippen des sulens dorsalis bedecken (Fig. 2, GH).

In Lenden- und Sakralmark haben wir also in der That ein bindegewebiges septum dorsale und damit auch eine fissura post. oder dorsalis, wie sie Arnold beschrieben hat. Sie reicht aber nie bis zur grauen Substanz und ist das Septum bedeutend sehwächer entwickelt, als die Piaduplicatur der fissura ant. s. ventralis.

Weitere Litcraturangaben über diese Frage findet man bei Bertelli1), welcher speziell die Beziehungen der Pia zu den Furchen des menschliclıen Rückenmarkes erörtert hat, weshalb ich hier etwas näher auf dic Arbeit Bertelli's eingehen muss. Dieselbe enthält einige Unklarkeiteu in der Darstciltung, weiche das Verständniss wesentich erschweren. So macht or keinen Unterschied zwischen sulcus, Furche und fissura, Spalte; wo eine bis zur grauen Commissur reichende fissura post. (ein sulcus nach Bertelli) beobachtet wird, handelt es sich grösstentheils um ein Kunstprodukt. Der suleus post. wird nun durch den Eintritt der Gefässe und dazwischen gelegenen leichten Einziehungen angedeutet, kann aber oft ganz vermisst werden. Nur im Bereiche des Lendenmarks vertieft sich der Sulcus und kann hier eine Tiefe von $1 \mathrm{~mm}$ erreichen. Diese Schilderung stimmt vollkommen mit unseren Beobachtungen an Querschnitten. Dann beschreibt aber Bertelli trotz des erwähnten Fehlens einer Fissura long. post. ein Septum, welches ebenso, wie das Septum long. ant. aus zwei Blättern der Pia bestehen soll (1. c. S. 70). Allerdings hat dasselbe nach Bertelli's Schilderung cinen ganz eigenthümlichen Bau; es ist netzförmig. und bestcht aus kleinen und zarten, unregelmässigen Lamellen und fadenförmigen Fortsätzen der Pia, welche untereinander anastomosiren, so dass weite Maschenräume entstehen, deren Ränder noch von einer zarten, gewellten Membran (membranella) umgeben werden. Durch

1) Rapporti della pia madre coni solchi del midello spinale umano. - Atti della Soc. Toscana. Sc. Nat. Pisa, Mem. Vol. XII, 1892, p. $57-75$. 
Beiträge zur Kenntniss des Stützgerüstes im menschl. Rückenmarke. 45

die Löcher dieses Maschenwerkes sollen Stränge von Marksubstanz durchgesteckt sein und diese Anordnung soll die Unmöglichkeit erklaren, das Septum zu entfernen, ohne eine künstliche Fissur zu erzeugen. Bertelli bildet in seincr Fig. 3 ruch ein solches Septum an einem Querschnitte durch die Halsanschwellung des Rückenmarkes ab, wo nach unseren allerdings nicht ausgedehnten Beobachtungen ein solches nicht vorkommt, wie in der Lendenanschwellung. Auch zeichnet er es als continuirlichen Bindegewebszug ohne Gefüsse, was nach seiner vorhergehenden Beschreibung nur so erklärt werden kann, dass es sich um die durch den Schnitt zufiallig abgetrennte Adventitia eines grösseren, senkrecht eindringenden Gefässes handelt.

Das von Bertelli beschriebeno hintere Septum soll bis zur grauen Commissur reichen und hier ebenfalls Fortsätze nach allen Seiten in dieselbe senden.

Diese ganze Darstellung scheint mir leicht geeignet, unrichtige Vorstellumgen zu erwecken, denn in der That kommt ein echtes, hinteres Septum nur dem Lendenmarke zu, während im iibrigen Rückenmarke nur Gefäisse mit ihren reichen Veräistelungen, umhïllt von ihrer Adventitia und bedeckt von der oberflachlichen Gliahülle eindringen. Die Grenzmembran dieser letzteren (siche weiter unten) haftet fest an der Adventitia und kann bei gewaltsamer Entfernung der Gefässe möglicherweise als die von Bertelli beschriebene Membranella zur Beobachtung gelangen.

Wir wenden uns nun zur oberflächlichen Gliahülle zurtick und lassen zunächst einige Angaben über ilıre Entwicklung und ihren feineren Bau folgen.

Betreff's ihrer Geschichte verweise ich noch auf Koelliker ${ }^{1}$ ), Key und Retzius"), sowie auf dic ausfülıliche Schilderung von Girke ${ }^{3}$ ), von dem auch der Ausdruck Gliahiille berribrt, während man sie früher als graue Rindenschichte bezeichnete.

Ich konnte diese Gliahülle an einer Reihe ziemlich frischer mensehlicher Riickenmarke untersuchen und zwar von drei hingerichteten Männem, welche ich mit 'T, $\mathrm{K}$ und $\mathrm{H}$ bezeichne, von einem 45 jährigen, an T'uberculose verstorbenen, No. 4 und von einem Individuum, dessen Rückenmark 5 Stunden p. m. zur Erhärtung gelangt war, No. 5. Ausserdem wurden die fertigen Sammlungspräparate von menschlichen und thicrischen Rückenmarken daraufhin untersucht.

Die Gliahülle ist nicht bei allen Individuen und auch beim Rückenmarke ein und desselben Individuums nicht an allen Stellen

1) Gewebelehre, 5. Anfl., S. 271.

2) l. c. I. Hülfte. Historisches über die Pia mater.

3) 1, c. I. Theil, S. 510. II. Theil, S. 152. 
gleich stark entwickelt. Auffallend deutlich ausgeprägt fand ich sie bei dem Rückenmarke von T, K, H, No. 4 und beim Schwein. Sehr schwach entwickelt, vielfach fehlend bei No. 5, sowie beim Meerschweinchen und Kaninchen. Am mächtigsten entfaltet erscheint sie an den Lippen der sulci und an den Austrittsstellen der Wurzeln ${ }^{1}$ ). Auch schien sie mir im Lendenmarke stärker entwickelt, als am Halsmarke desselben Individuums.

Als Maasse geben unter Anderen K ahler 25-100 $\mu$, 0 bèrsteiner $5-40 \mu$, ausnahmsweise bis zn $100 \mu$ und Koelliker 22- $45 \mu$ an. Ich fand ihren Dickendurchmesser bei $\mathrm{H} 9,75-$ $43 \mu$, bei No. $412-50 \mu$ und bei $\mathrm{T}$ im Maximum 82-107 $\mu$. Die excessive Entwicklung der Gliahülle kam in letzterem Falle noch durch einige, am Schlusse dieser Mittheilung geschilderten Verhältnisse zu besonderem Ausdruck. Hier will ich nur unter Hinweis auf die Fig. 5 erwähnen, dass an einzelnen Stellen der Rückenmarksoberfläche die Glia sogar in Form kleiner Büschel die der Gliahülle aufliegende Pialamelle durchbrach.

Sehr eigenthümlich gestaltet sich nun der feinere Bau dieser Gliahülle, welcher an unseren Präparaten (besonders bei T) sehr deutlich erkannt werden kann. An denselben scheint sie ausschiesslich aus feinen starren Fäserchen zu bestehen, von Zellkörpern ist, wie erwähnt, nichts wahrzunehmen (Fig. 2-6).

Die meisten älteren Beobachter erwähnen neben diesem faserigen auch einen körnigen Bau; auch an unseren Präparaten erhält man bei flüchtiger Betrachtung diesen Eindruck durch zahlreiche, zwischen den Fasern gelegene, stark glïnzende oder intensiv rothgefärbte kreisrunde Punkte oder Körner, die sich aber bei aufmerksamer Untersuchung mit dem $2 \mathrm{~mm}$ Apochromat von Zeiss sämmtlich als Faserquerschnitte erkennen lassen (Fig. 4 u. 5).

Die Fasern zeigen in der Hülle nämlich einen dreifachen Verlauf. Eine Lage, welche dem Markmantel unmittelbar aufliegt (Fig. 3, 4 und 5c), besteht aus ziemlich dicht gedrängten, circulär verlaufenden Fasern. Sie scheint gelegentlich als innerste, circulärfaserige Lage der Pia beschrieben worden zu sein. Durch diese Lage hindurchgesteckt treten aus dem Markmantel radiäre Fäserchen (Fig. 4,5r), welche theils direkt in die radiüren Gliasepten, theils in die Glianetze zwischen den Nervenfasern über-

1) Vgl. auch Paladino l. c. S. 12. 
gehen, so dass mit den circulären Fasern ein dichtes und festes Flechtwerk entsteht. Nach aussen überragen jedoch die radiären Fäserchen die circuläre Lage um ein weniges, so dass hier die Gliahïlle nur aus radiären Faserenden besteht (Fig. 2-6), welche sich direkt an die Pia anlegen; so entsteht unter der Pia ein Raum, Sp, welcher von diesen Faserenden durchzogen und gleichsam ausgespannt erhalten wird. Vielleicht ist dies der Zwischenraum zwischen Glia und Pia, den $\mathrm{His}^{1}$ ) als Epimedullarranm bezeichnet hat und dessen Vorhandensein von $\mathrm{Key}$ und Retzius mit Recht geläugnet worden ist ${ }^{2}$ ). In der That gehört der von mir beschriebene Raum ganz und gar der Gliahülle selbst an, während sich diese in der von Key und Retzius beschriebenen Weise so innig an die Pia anlegt, dass zwischen beiden kein freier Zwischenraum vorhanden ist, worüber weiter unten.

$\mathrm{Zu}$ dieser circulären und radiären Faserlage kommt nun noch als dritte eine longitudinale; sie findet an Querschnitten ihren Ausdruck in zahlreichen quergetroffenen Fasern, welehe zwischen den übrigen längsgetroffenen eingewebt erscheinen (Fig. 3-6) und welehe der ganzen Lage auch das körnige Ansehen verleihen. So erscheint also um das ganze Rückenmark, in innigster Verbindung mit seinem Stützskelete eine ausserordentlich feste Hülle gewebt, welche durch die Elastizität ihrer Elemente und die architektonische Verwendung derselben gewiss eine eminente Schutzvorrichtung darstellt.

Ueberall nun, wo Gefässe aus der Pia in das Mark eindringen, begleitet diese Gliahülle dieselben (Fig. 3, GS), eine von vielen Autoren $u$. A. von Gierke ${ }^{3}$ ) und Ranvier ${ }^{1}$ ) in ausgezeichneter Weise beschriebene Thatsache. Was mir dabei aber, besonders in tektonischer Hinsicht sehr bemerkenswerth erscheint, ist folgendes: Bei schwach entwickelter Gliahülle erseheinen

1) Ueber ein perivasculäres Canalsystem in den nervösen Centralorganen und über dessen Beziehung zum Lymphsystem. - Zeitschr. f. wiss. Zool. Bd. XV, 1865, S. 127.

2) Ich kann hier auf diese Verhältnisse nicht näher eingehen und erwähne nur, dass bereits Boll eine mit meiner Anschauung vollkommen übereinstimmende Darstellung der Frage, sowie ziemlich eingehende Kritik der Behauptungen von $H$ is gegeben hat.

3) $\mathrm{l} . \mathrm{c}$.

4) Technisches Lehrbuch, S. 972. 
stets die circuläre und longitudinale Faserlage reducirt, ja sie können ganz fehlen; nie jedoch fehlten die radiüren Fäserchen. So sehen wir auch an der Gliahülle der eindringenden Gefüsse, dass sich die Fasern stets senkrecht auf die Längsrichtung des Gefässes rings um dasselbe stellen, so dass sie auch hier wieder mit feinen, spitzen Enden auf die Oberfläche des Gefässes stossen und sich anscheinend mit demselben innig verbinden, ein Verhältniss, das bekanntlich zuerst $\mathrm{G}$ ol $\left.\mathrm{g}^{1}{ }^{1}\right)$ ausführlich geschildert hat. Dies ist eine Anordnung, die man einem Puffersystem vergleichen könnte und der gewiss eine grosse mechanische Bedeutung zukommt, wenn es sich darum handelt, die Gefässe vor Druck zu schïtzen. Dieselbe Erwägung hat für den perimedullüren Lymphraum bereits Gierke ${ }^{2}$ ) gemacht.

Was nun die Verbindung der oberflächlichen Gliahülle mit der Pia betrifft, so legt sich erstere nach Key und Retzius ${ }^{3}$, obne Modificationen ihres Gewebes zu erleiden, so innig an die gegen sie scharf und gut als Haut begrenzte intima piae an, dass zwischen beiden kein freier Zwischenraum vorhanden ist. Was die feineren Verhältnisse betrifft, so sollen die peripheren Ausläufer der Glia (Ependym-)Zellen (unsere radiären Gliafasern) nach Retzius4) sich hackenförmig umgebogen, wie der Griff eines Spazierstockes an die Pia anlegen, während sie nach Anderen, so z. B. S. Ramon y Cajal ${ }^{5}$ ) dort init einer kugelförmigen Anschwellung endigen. Eine ganz eigenthümliche Anschauung finden wir bei Gierke ${ }^{6}$ ) vertreten. Nach derselben liegt der Pia nach innen hin eine ungemein feine durehsichtige Endothelmembran fest an. Sie ist vollkommen homogen und gelang es Gierke nicht mit Deutlichkeit eine Zusammensetzung aus Endothelzellen an derselben nachzuweisen oder Kerne durch Färbung sichtbar zu

1) Sulla sostanza connetiva del cervello. - Rend. dell' Istit. Lomb. 1869. - Contribuzione alla fina anatomia degli organi centrali del sist. nerv. - Rivista clinica di Bologna, 1871.

2) 1. c. II. Theil, S. 152.

3) l. c. I. Hälfte, S. 146.

4) Ueber den Ban der Oberflïchenschicht der Grosshirnrinde beim Menschen und bei den Säugrethieren. -- Verhdlgn. d. biol. Vereines in Stockholm, 1891.

5) Sur l'origine et les ramifications des fibres nerveuses de la moelle embryonnaire. - Anat. Anz. Bd. V, 1890, S. 117.

6) l. c. II. Theil, S. 152 u. ff. 
machen. Aus der Gliahülle erheben sich nun unendlich viele feine und starke borstenartige Fäden, die Fortsätze der Gliazellen, welche sich an die Endothelmembran anlegen; dies geschieht theilweise mittelst einer kleinen Verdickung, theilweise verschmelzen sie vollkommen mit der Membran." Eine solche Membran soll auch die Gliahülle der Gefässe besitzen (Vgl. S. 48).

Thatsächlich kann man Querschnitte durch die Gliahülle, wo diese oft künstlich von der Pia abgehoben (Fig. 4, GM) erscheint, die erstere von einem vollkommen scharfen, glatten, membranartigen Contour begrenzt sehen. Derselbe zeigt bei näherer Betrachtung jedoch keinen Doppelcontour, wie eine Membran, sondern erscheint aus der Verschmelzung der radiären Faserenden gebildet ${ }^{1}$ ), welche oft in der von Retzius beschriebenen Weise umgebogen in den Grenzcontour eingehen.

Diese Membran setzt sich nun auch überall, wo Gefässe aus der Pia eindringen, auf die Adventitia derselben fort, d. h. auch die Enden der radiär zum Gefässverlauf gestellten Gliafäserchen verschmelzen zu einer limitans, so dass in der That Glia und Nervensubstanz, die ursprüngliche ectodermale Anlage scharf gegen die secundär eingewucherten mesodermalen Elemente abgesondert ist.

Fig. 3 zeigt diese Verhältnisse in recht instructiver Weise. Bei $\mathrm{T}$ erscheint die Grenzmembran GM von der Pia abgehoben und bildet einen Trichter, durch welchen ein Gefäss in ein Gliaseptum, GS, eindringt. Der Eintritt des Gefässes ist nicht in den Schnitt gefallen, erst sein weiterer Verlauf im Septum, wo es durch seine braune Farbe deutlich von der begleitenden Glia absticht. Dagegen ist der Schnittrand des Trichters, die Grenz-

1) Es wäre von grossem Interesse, die Entwicklung dieser Membran zu verfolgen, welche ja bereits am embryonalen Marke scharf ausgepräat vorhanden ist und die epitheliale Anlage gegen das umgebende Bindegewebe abgrenzt. Es ist sehr unwahrscheinlich, dass sie durch das Verschmelzen der radiären Gliafaserenden allein entsteht, da dieselben zu dünn sind und in zu weiten Abständen angeordnet erscheinen, um eine solche Membranbildung verständlich zu machen. Dass dieselbe aber eine eigenste Bildung der Neuroglia ist, scheint mir aus dem Verhalten der am Rückenmarke des Hingerichteten T. (Fig. 5) zufallig beobachteten, die Pia durchbrechenden Gliabüschel hervorzugehen welche ebenfalls ganz deutlich eine solche Membran (M) als Begrenzung zeigen. 
membran deutlich und lässt sich dieselbe noch auf die Oberfläche der Gefässadventitia verfolgen (GM) und ebenso lässt sich der ebenfalls radiäre Verlauf der Gliafasern des Septum auf diese Membran zu erkennen. Zuerst wurde diese Grenzmembran von Bergmann ${ }^{1}$ ) am Kleinhirn beschrieben und zwar bezeichnete er sie ganz richtig als zarte, strukturlose Lamelle, an welche sich senkrecht aus der grauen Substanz des Kleinhirns aufsteigende Fasern inseriren. Betreffs ihrer weiteren Geschichte verweise ich auf Henle und $\mathrm{Merkel}^{2}$ ) und die ausgezeichnete Arbeit von Boll, der sich selbst sehr eingehend mit der Membran beschäftigt hat und eine im Allgemeinen sehr zutreffende Schilderung derselben giebt. Nur hielt er sie für eine doppelt contourirte, kernhaltige Membran und fasste sie, soweit sie Gefässe begleitet, als ein Aequivalent der bindegewebigen Adventitia derselben auf, welche hier fehlen sollte. Dies war ein Irrthum; wie an meinen Präparaten ersichtlich ist, besitzen die meisten Gefässe eine oft mächtig entwickelte bindegewebige Adventitia, welche, wenn sie durch den Schnitt vom Gefäss losgetrennt worden ist, oft als stärkerer, radiärer Bindegewebsbalken imponirt.

Die Bildung dieser Bergmann'schen Limitans ist schon von Bergmann selbst, sowie von Boll mit der membrana limitans interna retinae verglichen worden; auch der Bildung des Schmelzoberhäutchens liesse sich diese Grenzlamelle der Gliahülle vergleichen. Keinesfalls handelt es sich um eine Endothelmembran, woraus sich ohne Weiteres die Misserfolge Gierke's erklären, die er bei dem Versuche, Kerne und Zellgrenzen in derselben nachzıweisen erfahren hat.

Wir haben bisher stets nur von "Gliafasern" gesprochen, ohne Rücksicht zu nehmen auf die in neuerer Zeit immer mehr zur Geltung gelangende Auffassung, dass die Neuroglia nur aus verästelten Zellen bestehe und somit das, was wir als Fasern bezeichnen stets nur Zellausläufer wären.

Bekanntlich hat schon Koelliker ${ }^{4}$ ) im Jahre 1867 die

1) Notiz über einige Strukturverhältnisse des Cerebellum und Rückenmarks. - Zeitschr. f. rat. Med. N. F., Bd. 8, 1857, S. 360.

2) 1, c. S. 60 .

3) 1. c. S. 86 .

4) Gewebelehre, 5. Aufl. 
Neuroglia für eine einfache Bindesubstanz erklärt, „die ganz und gar aus Netzen sternförmiger Bindesubstanzzellen oder aus einem Gerüste kernloser, aus den Zellennetzen hervorgegangener vielfach unter einander verbundener Fasern und Bälkchen besteht" und dieses Netz dem Reticulum im adenoiden Gewebe gleich gestellt. Deiters ${ }^{1}$ ) hat die Zellen der Neuroglia zuerst genau beschrieben und $\mathrm{Golg}^{2}{ }^{2}$ ) war der erste, welcher mit Entschiedenheit betonte, ndass das ganze interstitielle Gewebe der weissen und grauen Substanz der Centren aus Strahlenzellen und ihren Fortsätzen gebildet werde."

Durch die weiteren Arbeiten von Boll' ${ }^{3}$ ), Jastrowitz ${ }^{4}$ ), Ranvier ${ }^{5}$ ), Gierke ${ }^{6}$ ), sowie die neuesten von S. Ramon $y$ Cajal ${ }^{7}$ ), v. Lenhossek ${ }^{8}$ ), Lavdowsky ${ }^{9}$ ), van Gehuchten ${ }^{10}$ ) und vielen Anderen wurde die Natur dieser Zellen genauter erforscht und ihre wesentliche Bedeutung für die Bildung der Nenroglia nachgewiesen.

Gegenwärtig besteht nur eine Controverse zwischen den Anhängern der Lebre Golgi's und allen Jenen, welche hauptsäch. lich nach dessen Methode gearbeitet haben einerseits und Ranvier und dessen Anhängern andererseits. Wälnrend die ersten stets nur von sternförmigen Zellen mit echten Zellausläufern sprechen, vertrat Ranvier schon frühzeitig die Ansicht, dass die Fasern der Neuroglia eine grosse Unabhängigkeit von den Zellen besitzen. Nach Ranvier besteht die Neuroglia bloss aus Fibrillen verschiedener Länge, die sich vielfach kreuzen und durchflechten. An den Kreuzungsstellen der Fasern erscheinen Zellen in Gestalt flacher Plättchen eingelagert, in deren Protoplasma die Fibrillen bloss eintauchen, ohne mit den Zellen selbst in Verbindung zu treten. Die verästelten Zellen sind demnach Kunstprodukte durch Verklebung der cchten Zellen mit den Kreuzungsstellen der feinen Fibrillenbuindel entstanden.
1) 1. c.
2) 1. c.
3) 1. c.

4) Studien über die Encephalitis und Myelitis des ersten Kindesalters. Arch. f. Psych. II, 1870; III, 1871.

5) l. c.

6) l. e.

7) 1 , c. und an vielen anderen Orten.

8) l. c. 9) l. c.

10) La structure des centres nerveux. La moelle épinière et le cervelet. - La cellule, T. VII, 1891, p. 104. 
Während sich Schwalbe, Weigert, Edinger der Ansicht Ranvier's rickhaltlos anschlossen, vertrat Gierke eine etwas andere Ansicht, indem er die Anlagerung der Gliafasern an die Zellen durchaus nicht wie Ranvier als etwas regelmässiges erklärte, sondern glaubte, dass sich dieser Zustand erst bei zunehmender Verhornung der Fasern bei älteren Individuen entwickle. Selbstständige, verhornte Gliafasern können dadurch entstehen, dass bipolare Zellen ganz in der Bildung ihrer Fortsütze aufgehen.

Durch die Beobachtungen an unseren Präparaten nun, wo man an der Oberfläche eine grosse Masse reinen Gliagewebes vor sich hat, wird man entschieden zu der Ansicht dieser letzteren Autoren gedrängt, dass im erwachsenen Rtickenmarke, wenigstens in der oberflächlichen Gliahülle und im Bereich der weissen Substanz die Gliafasern zum grössten Theil unabhängig von den eingelagerten Zellen sind.

Die Bilder, welche in dieser Beziehung die Golgi'sche Methode giebt, scheinen mir nicht ganz einwurffrei zu sein und sind dieselben auch zumeist an embryonalen oder sehr jugendlichen Rückenmarken gewonnen. Dass in diesen frühen Entwicklungsstadien in der That die Gliafasern den Werth von Zellausläufern besit\%en, ist sehr wahrscheinlich. Dagegen sprechen die Bilder im erwachsenen Rückenmarke entschieden für die Unabhängigkeit der Fasern. An Weigerts wie an meinem Präparaten tritt dies deutlich hervor, wemn auch bei der Färbung W eigert's häufig der Zellkern mitgefärbt sein soll. Dass man an meinen Präparaten den entschiedenen Eindruck bekommt, als bestände die Gliahïlle nur aus Fasern, habe ich schon erwähnt und verweise ich auf die Figg. 2--6. Für die oberflächliche Glialage, die unserer Beschreibung in erster Linie zu Grunde lag, betonte schon Golg ${ }^{1}$ ) selbst und ẹbenso Paladino, dass in ihr die Zellkörper selten sind, die ganze Lage einen festeren Bau besitzt und die Zellausläufer durch grössere Stärke und Starrheit ausgezeichnet sind. Der von Ranvier betonte mikrochemische Unterschied zwischen Zellen und Fasern wird aber noch durch einige andere Methoden sehr deutlich; so besonders nach Doppelfärbung mit BoraxcarminIndigocarmin. Da erscheinen die Zellkerne roth gefärbt und um

1) Sulla fina anatomia degli organi centrali etc., Milano 1886. 
dieselben kann man manchmal noch deutlich ein spärliches, zart rosa gefärbtes Protoplasma wahrnehmen, an welches sich dann unmittelbar die intensiv grüngefärbten Fasern anlegen. An Präparaten, die einfach mit Hämatoxylin und Eosin doppelt gefärbt wurden, sieht man auch die Kerne lebhaft blau gefärbt und kann die roth gefärbten Fasern oft ununterbrochen unmittelbar über dieselben weg streichen sehen, wie dies Ranvier an Isolationspräparaten beschrieben hat. Auch ist es an solchen Präparaten auffallend, dass man in der Gliahülle oft 3-4 Kerne in unmittelbarer Nachbarschaft sieht, während der Verlauf der Fasern an solchen Stellen nicht anders erscheint, als dort, wo auf weite Strecken kein Kern zu sehen ist. Auch sieht man an so behandelten, wie an Isolationspräparaten nie so mächtige Zellkörper, wie sie an Golgi-Präparaten abgebildet werden.

Alle diese Umstände lassen mir die Anschaunng Gierke's als die wahrscheinlichste erscheinen, dass die Fasern sich secundär durch eine Art Verhornungs- oder Cuticularisirungsprozess immer mebr von den ursprünglichen Zellen sondern und zuletzt ganz unabhängig von denselben werden können.

Damit soll nicht in Abrede gestellt werden, dass auch noch im erwachsenen Rückenmarke echte, sternförmige Gliazellen vorkommen können; darüber müssten besonders Untersuchungen über die Art und Weise, wie Defekte an Nervensubstanz durch Gliamassen ersetzt werden, Aufschluss geben.

Schliesslich muss ich noch einer eigenthtimlichen Beobachtung gedenken, welche ich in erster Linie an dem Rückenmarke des Eingangs erwähnten Hingerichteten gemacht habe und später sonderbarer Weise an einigen Rückenmarken anderen Justificirter bestätigt fand. In diesen (3) Fällen handelte es sich ausnahmslos um eine mächtig entwickelte oberflächliche Gliahülle, während in einem vierten Falle dieselbe nur schwach ausgeprägt war. Die nachfolgende Schilderung bezieht sich hauptsächlich auf das Rückenmark des hingerichteten $T$, bei dem die Verhältnisse am auffälligsten ausgeprägt waren.

An Querschnitten des Rückenmarks (es wurde hauptsächlich Hals-, Lenden- und Sakralmark untersucht) bieten die mit getroffenen Nervenwurzeln theils das gewöhnliche Bild, theils zeigen sie ein sehr merkwürdiges Verhalten. Hat man die Schnitte ein- 
fach nach Kultschitzky's modificirter Methode mit EssigsäureHämatoxylin gefärbt, so treten zwischen den schwarz gefärbten Markröhren ganz isolirte, scharf abgegrenzte Bündel von wechselndem, bis zu sehr grossem Durchmesser hervor, welche eine körnige, spongiöse Struktur besitzen und hellbraun, wie das Bindegewebe gefärbt erscheinen. An entsprechenden Längsschnitten überzeugt man sich, dass es sich um rundliche Bündel handelt, welche aus dünnen, dicht gedrängten Fäserchen zusammengesetzt erscheinen. An manchen Wurzelquerschnitten wird das Bild fast nur von diesen eigenthümlichen Bündeln beherrscht; so fand ich an einem vorderen Wurzelbündelquerschnitte, dessen grösster Durchmesser $0,432 \mathrm{~mm}$ betrug, sieben solche Bündelquerschnitte, von denen der grösste $125 \mu$, die mittleren $50-80 \mu$, die kleinsten $38 \mu$ im Durchmesser zeigten. An mit Kernfärbemitteln behandelten Schnitten liessen sich vereinzelte Kerne in den Bündeln nachweisen, so dass das Bild sehr an Querschnitte markloser Nervenbündel erinnerte. Darauf hin angestellte Controlluntersuchungen (Vergoldung der Schnitte nach Freud's Methode, Vergoldung frischer Nervenwurzeln nach Drasch mit nachfolgendem Zerzupfen) ergaben durchaus negative Resultate. Ein deutliches Licht auf die Bedeutung dieser Bündel warf erst die nachfolgende Färbung in dünner Eosinlösung. Sie nahmen dieselbe distincte Färbung an, wie die mächtig entwickelte Gliahülle. An solchen Präparaten liessen sich noch weitere Einzelheiten erkennen. War gerade der Austritt einer Wurzel in den Schnitt gefallen, so sah man, dass dieselbe zunächst von der mächtigen Gliahülle ebenfalls eine breitere, oberfächliche Hülle erhielt (Fig. 6). Diese besteht aus mehreren Lagen circulär verlaufender Fasern, durch welche radiär verlaufende durchgesteckt erscheinen, wie an einem Korbdeckelweidengeflechte; im Inneren des Bündels bilden die Fasern ein Flechtwerk um die einzelnen Nervenfasern, so dass die schwarz gefärbten Markringe der letzteren durch die roth gefärbten Fasern vollkommen isolirt erscheinen (Fig. 3). Der epineurale Piaüberzug sticht wieder scharf gegen diese roth gefärbten Fasern ab.

Durchsucht man die Nervenwurzel von ihrem Austritte in distaler Richtung fortschreitend, so ändert sich das beschriebene Bild zunächst dahin, dass die circuläre, oberflächliche Faserlage allmählich aufhört und nur das Flechtwerk zwischen den mark- 
haltigen Fasern vorhanden bleibt - ähnlich, wie im weissen Rückenmarksmantel. Dieses Flechtwerk ist aber oft so reichlich entwickelt, dass die Nervenfaserquerschnitte in demselben weit von einander getremnt erscheinen. Noch weiter distalwärts sammeln sich die Fasern des Flechtwerkes endlich zu geschlossenen, dichten Bündeln längsverlaufender Fasern, die gegen die Nervenfasern durch eine oberflächliche, membranartige Schichte scharf abgegrenzt erscheinen (Fig. 7). Diese Bündel liegen bald oberflächlich, bald rings von Nervenfasern umgeben, werden immer schmächtiger, um sich endlich, nach verhältnissmässig kurzem Verlaufe von wenigen mm, noch ehe die Wurzeln den Wirbelkanal verlassen, kegelförmig zugespitzt zwischen den Nervenfasern zu verlieren.

Wie man aus dieser Schilderung ersieht, kann man nicht zweifeln, dass es sich hier um Neurogliamassen handelt, welche vom Centralorgan weit in die aus- beziehungsweise eintretenden Wurzeln vorgedrungen sind. Es ist dies eine besonders reichliche Entwicklung des Stittzgewebes, welche mit der ebenfalls ungewöhnlich starken Entwicklung der Gliahülle zusammenzulängen scheint.

In ähnlicher Form fand ich diese extramedullären Gliabündel nur noch in einem Rückenmarke, das ebenfalls einem Hingerichteten entnommen war. Hingegen vermisste ich sie in einigen anderen untersuchten Rïckenmarken vollständig.

Entwicklungsgeschichtlich wäre das Vorkommen leicht verständlich, sind ja doch vereinzelte Ganglienzellen in den Wurzeln schon lange gefunden worden (eine solche wurde zufällig auch in der in Fig. 6 abgebildeten Wurzel bei $\mathrm{Gz}$ gesehen) und ebenso, wie diese ausgewandert sein müssen, können auch die Gliazellen ausgewandert sein.

Eine andere Frage ist es jedoch, ob es sich hier um eine individuelle Variation, um eine übermässige Entwicklung sonst normaler Verhältnisse oder um ein pathologisches Vorkommniss handelt. Die Nervenfasern in den Wurzeln boten im Allgemeinen keine abnormen Erscheinungen; in einer oder der anderen schien mir wohl der Achsencylinder gequollen, dann. war aber wieder an ganzen Wurzelquerschnitten nicht die geringste pathologische Veränderung wahrzunehmen. Bekanntlich wandert Glia immer dort, wo im Centralnervensystem Nervensubstanz durch Erkran- 
kung ausfällt, in die leer werdenden Stellen ein; gegen eine solche Möglichkeit spricht aber in unserem Falle schon die Art der Anordnung der Gliafasern, wie ich sie in Fig. 6 abgebildet habe. Auch konnte ich für die Annahme, dass es sich hier um ein pathologisches Vorkommniss handle, weder in der Literatur der Nervenpathologie ein Analogon finden, noch von Seite der pathologischen Anatomen einen Aufschluss erhalten. Dagegen liegen Beobachtungen vor, welche für die erste, oben ausgesprochene Ansicht zu verwerthen sind.

Dass wir in der eingehenden Untersuchung über die mensehlichen Rückenmarkswurzeln von Siemerling ${ }^{1}$ ) nichts ähnliches beschrieben finden, könnte man damit erklären, dass $\mathrm{S}$ i e merling in dem einzigen Falle, von dem er allerdings alle Wurzeln untersucht hat, die letateren $3-4 \mathrm{~mm}$ von ihrem Austritte aus dem Rückenmark abgetrennt hat. Dagegen finden sich Andeutungen uber das Vorkommen von Neurogliafasern in den Wurzeln bei Köliker ${ }^{2}$ ), Lavdowsk ${ }^{3}$ ) und Edin$\left.\mathrm{g} \mathrm{er}^{4}\right)$. Ersterer erwähnt an der citirten Stelle, dass von der oberflächlichen Hülle in Begleitung der Blutgefässe und z. Th. auch der Nervenwurzeln eine grosse Anzahl von Balken und Fasern in das Inmere hineinziehen, welche alle aus Neuroglia bestehen und Scheiden um die betreffenden Theile bilden, die bei den Nervenwurzeln auch zwischen die einzelnen Fasern sich erstrecken. Lavdowsky lässt in seiner bereits erwilhnten Fig. 7, Taf. XVI anch einige Gliafasern als Zellfortsätze in eine dorsale Wurzel eintreten.

Ed in ger erwähnt kurz, dass das Net\% der Neuroglia als breite Zone fast reiner Gerüstsubstanz die ganze Oberfläche von Gehirn und Rückenmark überzieht und sich auch zapfenförmig noch ein Stück in die einzelnen Wurzeln hinein erstreckt.

Ganz analoge Verhältnisse jedoch, wie die hier am Rïckenmark beschriebenen, wurden von 'T homsen und 0 ppenheim an Hirnnerven zuerst beobachtet, von Ersterem auch theilweise

1) Anatomische Untersuchungen über die menschlichen Rückenmarkswurzeln. Berlin, 1887.

2) Gewebelehre, 6. Aufl., 1893, II. Bd., I. Th., S. 151.

3) l. c.

4) l. c. S. 16 . 
vollkommen mit unserer Schilderung ïbereinstimmend beschrieben, jedoch falsch gedeutet.

Eine Bestätigung der Befunde dieser Autoren und auch die richtige, mit unserer übereinstimmende Dentung derselben wurde dann von Staderini gegeben, dessen Mittheilung mir durch Zufall erst jetzt bekannt geworden ist. Thomsen beschrieb zuerst ${ }^{1}$ ) in einem $\mathrm{N}$. abducens, beziehungsweise oculomotorius von Alkoholisten kleinere, rundliche, multiple Plaques, die, in sonst ganz gesundem Nervengewebe liegend und von letzterem scharf abgesetzt aus einer körnigen Substanz bestanden, welche sich mit Carmin intensiv fürbte und in welcher sich noch vereinzelte gesunde oder atrophische Nervenquerschnitte nachweisen liessen. Er fasste sie damals als Degenerationsherde auf.

Bald darauf beschrieb $O$ p pen h e i m ${ }^{2}$ ) die gleichen Herde im Facialis bei einem Fall von Bulbärparalyse ohne anatomischen Befund und sprach, ohne nälier darauf einzugehen, die Ansicht aus, dass es sich um ein, noch nicht näher gekanntes, normales Vorkommniss handle, eine Ansicht, der sich in einer weiteren Mittheilung auch $\mathrm{Thomsen}^{3}$ ) anschloss. Dieser konnte das Vorkommen der fraglichen "Herde" an Querschnitten des Oculomotorius, Abducens und Facialis constatiren; einmal heobachtete er einen solchen "Herd" auch in einer hinteren Lumbalwurzel. Dass Thomsen die wahre Bedeutung dieser "Herde" als Bündelquerschnitte nicht erkannte, liegt hauptsächlich wohl darin, dass er fast nur Querschnitte untersucht hat; denn wenn er auch bemerkt (S. 463): „An Längsschnitten erseheinen die Herde als ku'z spindelförmige Gebilde", so hat er hier offenbar Schrägschnitte vor sich gehabt. Die genauere Schilderung Thomsen's jedoch, sowie seine Abbildung 1 zeigen aber deutlich die vollkommene Uebereinstimmung mit unseren Querschnittsbildern. Zum Beweise dieser Uebereinstimmung hebe ich kurz folgendes aus Thomsen's Beschreibung hervor. Die Herde

1) Beitrag zur multiplen Alkohol-Neuritis. - Mendel's (neurologisches) Centralblatt, 1887, S. 22.

2) Ueber einen Fall von chronischer progressiver Bulbärparalyse ohno anatomischen Befund, - Mendel's Centralblatt, 1887.

3) Ueber eigenthümliche aus.veränderten Ganglienzellen hervorgegangene Gebilde in den Stämmen der Hirnnerven des Mensehen. Virchow's Arch. Bd. 109, 1887. 
bestehen aus einer grobkörnigen, bezw. feingestrichelten Substanz, die durch vielfältige Lücken und Hohlräume zerklüftet ist und in der man zuweilen stark lichtbrechende Körper von der Grösse eines Zellkernes constatirt. Sie bleiben absolnt unverändert bei Einwirkung von Essigsäure, $\mathrm{KOH}$ oder Aether; mit Hämatoxylin lassen sich in denselben spärliche Kerne nachweisen. Ihre Grösse schwankt; einige haben einen Durchmesser von 2-3, andere einen solchen von 10-20 Nervenfasern. Das umgebende Gewebe besteht aus absolut gesunden und unveränderten Nervenfasern. Von Interesse ist eine zweite Form dieser eigenthümlichen Substanz, wie sie Th. beschreibt: Sie umgiebt in Form eines Kranzes oder Bandes ein grösseres Nervenbündel und sendet unregelmässige Fortsätze zwischen die umgebenden normalen Fasern oder aber es schiebt sich der Herd fast in Gestalt eines breiten Bindegewebsseptums zwischen die Nervenbündel hinein. Am häufigsten fand er sie dort, wo die Nerven extracerebral werden. Th. lässt diese Herde aus veränderten Ganglienzellen hervorgehen, obwohl ihm selbst diese Erklärung nicht ausreichte zum Verständniss des Vorkommens von Nervenfasern innerhalb der Herde, sowie ihrer kranz- oder septumartigen Form.

Die richtige Erklärung dieses eigenthümlichen Vorkommens, nebst einer Bestätigung und Bereicherung der objectiven Befunde Thomsen's gab dann Staderini ${ }^{1}$ ) in einer Mittheilung, welche mir, wie erwähnt, erst jetzt durch Zufall bekannt geworden ist, während ich meine ersten einschlägigen Beobachtungen unter dem Datum Juni 1890 verzeichnet finde. Staderini beschreibt dieselben Herde ansser in den drei von Thomsen genannten Nerven auch noch im Trochlearis (in dem sie weder Thomsen noch 0 p penheim hatten finden hönnen) und im Vagus. $\mathrm{Er}$ versuchte verschiedene Fürbungen (Weigert's Hämatoxylin, Fuchsin, B ea le's Carmin) und fand, dass die körnigen Massen stets eine von der Nervenfärbung verschiedene zeigen.

Bei näherer Untersuchung erwiesen sich dieselben zusammengesetzt aus zahlreichen, feinen Fibrillen, welche unter einander verflochten sind und ein Netzwerk mit gestreckten, unregel-

1) Contributo allo studio del tessuto interstiziale di alcuni nervi craniensi dell' uomo. - Monitore zool. ital. Anno I, No. 12, 1890. 
mässigen Maschen bilden, in welchem man mit Carmin verschicdene runde Zellkerne nachweisen konnte. Durch das Studium von Längsschnitten und Querschnittsserien konnte er weiter constatiren, dass es sich um Bündel handle, welche wie Scheidewände zwischen den Nervenfasern, die stets ein normales Aussehen zeigten, eingeschaltet erscheinen und centralwärts sich oft in ein Netzwerk auflösen, von welchem gleichmässig vereinzelte Nervenfasern umschlossen werden, während sie peripherwärts nach einem Verlaufe von $21 / 2-3 \mathrm{~nm}$ kegelförmig zugespitzt enden. Für die richtige Erkenntniss der Natur dieser Faserbündel aber war am entscheidendsten die Beobachtung, dass die oberfläehliche Gliahülle direkt in jene Stränge durch Vermittlung der Netzwerke ibergeht und dass St. mittelst der Golgi'schen Methode typische Neurogliazellen in diesen Strängen nachweisen konnte.

Aus vorstehenden Mittheilungen ergiebt sich die vollkommene Analogie unserer Beobachtungen am Rutckenmarke mit denen an den Gehirnnerven.

Die wesentlichen Ergebnisse der vorliegenden Untersuchungen wurden bereits in Form einer vorläufigen Mittheilung unter dem Titel „Die oberflächliche Gliahiille und das Stützgerïst des weissen Rückenmarksmantels" im „Anatomisehen Anzeiger, IX. Bd., No. 8 mitgetheilt.

Für die künstlerische Ausführung der Abbildungen bin ich Herm Dr. Amand Schlossarek, Sekundärarzte am St. AnnaKinderspitale zu besonderem Danke verpflichtet.

Während der zweiten Correktur dieser Arbeit kam mir die Dissertation von Cl. Sala y Pons „La Neuroglia de los Vertebrados", Madrid, Junio 1894, gedruckt zu Barcelona, in die Hände.

Dieselbe enthält im Wesentlichen eine Zusammenfassung der Arbeiten über die Neuroglia der Wirbelthiere, jedoch fast ausschliesslich nur soweit sie Untersuchungen mittelst der Methode von Golgi betreffen, weshalb ich hier von einer eingehenden Besprechung derselben absehen kann. 


\section{Erklärung der Abbildungen auf Tafel IV.}

Sämmtliche Figuren sind Präparaten me nschlicher Rückenmarke entnommen, welche in M üller'scher Flüssigkeit gehärtet und nach der eingangs im Text beschriebenen Methode mit Essigsäure-Hämatoxylin und Eosin gefärbt worden waren.

Fig. 1. Septum long. post. Unteres Dorsalmark eines an Tbc. Verstorbenen. HS Hinterstrang, SLP septum long. post., reines Gliaseptum, $S P M$ septum paramedianum, $G H$ oberflächliche Gliahülle, $P$ Pia. Vergr. 126.

Fig. 2. Septum und sulcus long. post. Lendenmark eines Hingerichteten (T). HS Hinterstrang, PS Bindegewebslamelle der Pia als Septum in der fissura long. post., $G H$ Gliahülle desselben, welche direkt auf die Lippen des sulcus long. übergeht $\left(G H_{l}\right)$. $S p$ epimedullärer Spaltraum mit radiären Gliafaserenden. Bei $G B$ hervorbrechende Gliabüschel. $P$ Pia, A Arterie, VVenen. Vergr. 81.

Fig. 3. Randpartie eines Seitenstranges $S S$ vom Sakralmarke eines Hingerichteten. $P$ Pia mit Gefässen, $G H$ Gliahülle mit dem epimedullären Spaltraum $\$ p$, durch welchen die radiären Gliafaserenden laufen. Bei $G S$ ein stärkeres Gliaseptum mit einem Gefässe, welches aber nicht bis zur Pia verfolgt werden kann, da aussen (bei $T$ ) der Schnitt unter die Abgangsstelle gelallen ist. Dagegen wird hier die Grenzmembran der Gliahülle , GM, sichtbar, welche sich bei $T$ trichterförmig einsenkt zur Begleitung des Gefässes und noch weiter die Adventitia des letzteren bedeckt $(G M)$, auf welche wieder radiäre Gliafaserenden zulaufen. Vergr. 126.

Fig. 4. Partie der oberflachlichen Gliahülle , $G H$, künstlich von der Pia , $P$, abgehoben, so dass die Grenzmembran der Glia , $G M$, deutlich sichtbar wird. In die Bildung derselben gehen die radiären Gliafasern , $r$, ein. c circuläre Gliafasern, die longitudinalen als Punkte zwischen den ersteren sichtbar. $S p$ epimedullärer Spaltraum. - Lendenmark eines Hingerichteten. Vergr. 443.

Fig. 5. Die Stelle $G B$ der Fig. 2 bei 443 facher Vergrösserung. Die Pia , $P$, durchbrechende Gliabüschel, welche sich ebenfalls mit einer membrana limitans , $M$, umgeben haben. Die übrigen Bezeichnungen wie oben.

Fig. 6. Austretende, vordere Rückenmarkswurzel mit Gliaumhüllung ,GH,. Sakralmark eines Hingerichteten. Bei $G z$ eine Ganglienzelle, bei $g$ ein Gefäss. Die übrigen Bezeichnungen wie oben. Vergr. 126.

Fig. 7. Ein vorderes Wurzelbündelchen bald nach seinem Freiwerden aus dem Lendenmark mit 8 Gliasträngen ,Gst, im Querschnitt. Bei $g$ ein Blutgefäss. Vergr. 81 . 


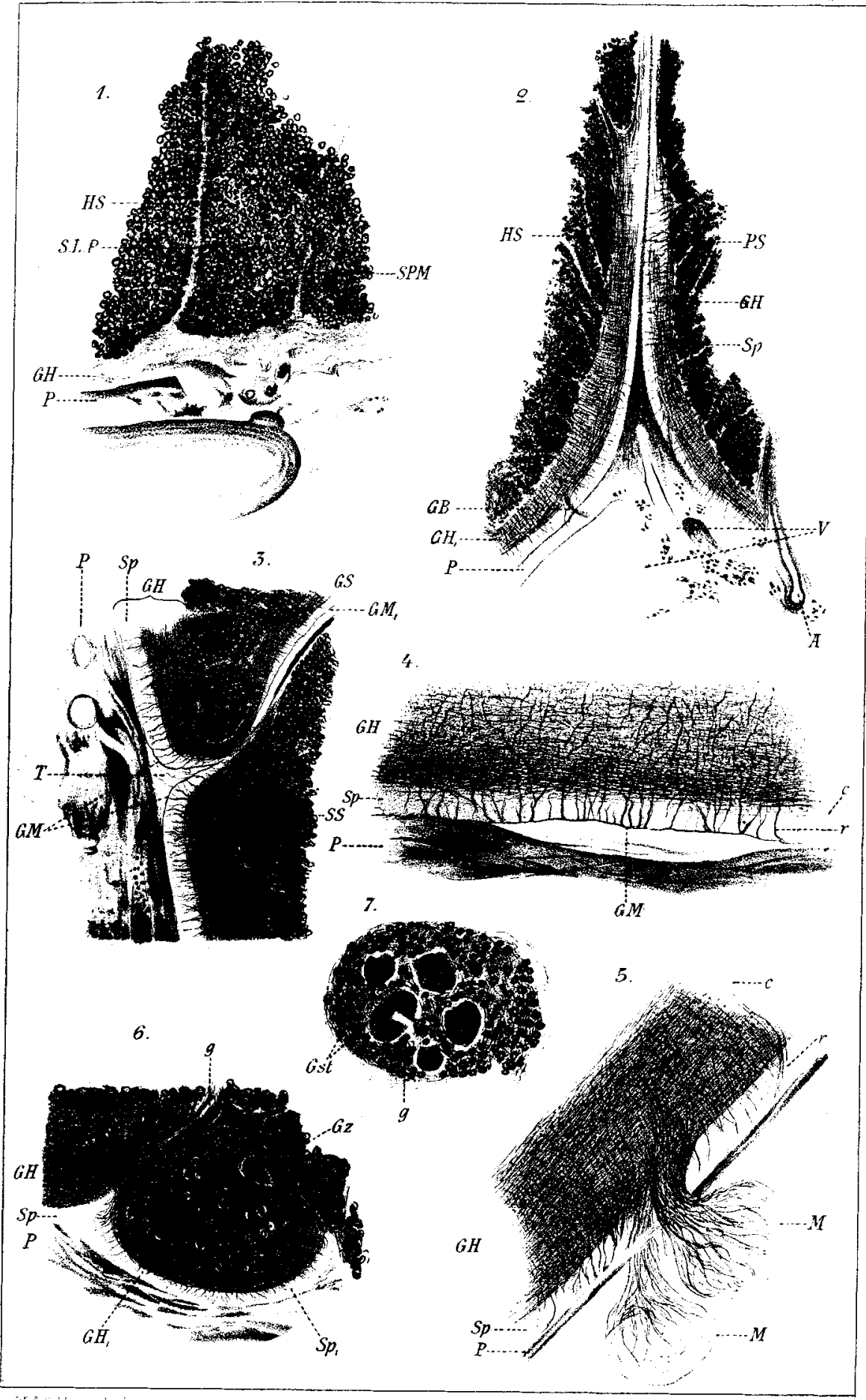

Luth Anst $v$ Wemes a hinter, Frankfurt $\$$ M. 